\title{
INOVAÇÃO EDUCACIONAL E RECURSOS DIDÁTICOS NO TRABALHO DOCENTE 1
}

\author{
Educational innovation and didactic resources in teaching work
}

OLIVEIRA, Maria Rita Neto Sales ${ }^{2}$

\begin{abstract}
RESUMo
Discute-se inovação educacional, evidenciando-se a importância do seu tratamento na atualidade. Defendese que o trabalho na educação implica caráter teleológico e é com esse reconhecimento que se pode tratar de inovações na área. Dentro disso, tem-se por objetivo contribuir para a compreensão do caráter inovador ou não de recursos didáticos no trabalho docente. Com esse objetivo, o texto contém uma reflexão de caráter teórico sobre a temática. Essa inclui dados de estudo integrativo exploratório, ao qual se acrescentou estudo dos áudios, vídeos e textos que compuseram o n. 1 de 2020 da revista on-line Educação Básica em Foco. Com base nesses estudos, abordam-se concepções sobre inovação, assumindo-se a posição dialética pela qual as inovações educacionais devem estar a serviço de finalidades de transformação, nos âmbitos individual e coletivo. A partir dessa posição e pelas conclusões dos estudos mencionados, identificam-se recursos didáticos potencialmente inovadores no trabalho docente: as práticas colaborativas, dialógicas e o uso crítico das tecnologias digitais de informação e comunicação (TDIC's). Neste último caso, discute-se também o seu uso na situação da pandemia pelo coronavírus. Conclui-se que os recursos didáticos assumem caráter inovador ou não ao se aproximarem mais ou menos daquelas finalidades, considerando-se os limites dessa condição, no interior das contradições societárias. Finalmente, levanta-se a questão da inclusão digital como um direito.
\end{abstract}

Palavras-chave: Inovação educacional. Recursos didáticos inovadores. Tecnologias digitais da informação e comunicação.

\begin{abstract}
Educational innovation is discussed, highlighting the importance of its treatment at the present time. It is argued that the work in education implies teleological character and it is with this recognition that one can deal with innovations in the area. Within this, the objective is to contribute to the understanding of the innovative character or not of teaching resources in teaching work. To this end, the text contains a theoretical reflection on the subject. This includes data from an exploratory integrative study, to which was added study of the audios, videos and texts that made up the $\mathrm{n}$. 1 of 2020 of the online journal Educação Básica em Foco. Based on these studies, conceptions about innovation are approached, assuming the dialectical position by which educational innovations should be at the service of transformation purposes, in the individual and collective spheres. From this position and the conclusions of the studies mentioned, we identify potentially innovative teaching resources: collaborative dialogic practices, and the critical use of digital information and communication technologies (TDIC's). In the latter case, it is also discussed its use in the situation of the coronavirus pandemic. It is concluded that teachig resources assume an innovative character or not when approaching more or less those purposes, considering the limits of this condition, within society contradictions. Finally, the issue of digital inclusion is raised as a right.
\end{abstract}

Keywords: Educational innovation. Innovative teaching resources. Digital technologies of information and communication.

\footnotetext{
${ }^{1}$ Conteúdos deste texto seniram de base para apresentações em eventos científicos sobre o tema.

2 Ph.D. na área da educação pela Florida State University. Professora Titular aposentada da Faculdade de Educação da Universidade Federal de Minas Gerais (FaE-UFMG) e do Centro Federal de Educação Tecnológica de Minas Gerias (CEFET-MG), trabalhando como pesquisadora voluntária em ambas as instituições. E-mail: mariarita2@dppg.cefetmg.br.
}

Trabalho \& Educação | v.30 | n.1 | p.177-190 | jan-abr | 2021 


\section{INTRODUÇÃO - A IMPORTÂNCIA DO ESTUDO DO TEMA}

O objetivo deste texto é o de contribuir para a compreensão do caráter inovador ou não de recursos didáticos no trabalho docente, a partir de problematização acerca da inovação na área educacional.

Uma primeira ideia que se pode trazer para a discussão refere-se à importância do tratamento do tema em pauta. A esse propósito, convém lembrar que discutir a inovação educacional como base para a compreensão da natureza de recursos didáticos vai ao encontro da posição de que o trabalho docente envolve ou, pelo menos, deveria envolver recursos inovadores, no contexto contraditório da contemporaneidade.

A questão da inovação tem estado presente na produção intelectual de várias áreas de conhecimento, incluída a educacional. Neste caso, importa registrar que o Fórum Mundial de Educação Profissional e Tecnológica, ocorrido no Brasil, em Pernambuco, em maio de 2015, teve o tema da inovação presente em seu tema geral: Diversidade, Cidadania e Inovação (ABMES, s.d.).

Acrescenta-se que a questão da inovação vem sendo há muito incorporada como área de atuação regular de instituições de educação superior no Brasil. Essas passam a contemplar, de forma sistemática, a área da inovação ao lado do ensino, da pesquisa e da extensão. Passam, inclusive, a definir a gestão dessa área em nível de pró-reitorias, como evidencia, por exemplo, a estrutura organizacional dos Institutos Federais de Educação Profissional, Científica e Tecnológica, tal como discutida por Fernandes (2009).

No âmbito didático-metodológico, em particular, destaca-se o Congresso de Inovação e Metodologias no Ensino Superior e Tecnológico, realizado anualmente, desde 2015, na Universidade Federal de Minas Gerais (UFMG), tendo adquirido caráter interinstitucional na sua quinta versão que está programada para ocorrer em novembro deste ano de 2020 (CIM, s.d. $)^{3}$. No âmbito em pauta, convêm destacar ainda a presença do tema no Encontro Nacional de Didática e Prática de Ensino (Endipe), especialmente em suas versões de 2012, 2014 e 2016 (XVI ENDIPE, 2012a, 2012b; XVII ENDIPE, 2014a, 2014b, 2014c, 2014d; BVS, s.d.).

Finalmente, no momento atual da pandemia pelo coronavírus, que vem sendo enfrentada no Brasil e no mundo, o ensino remoto na educação escolar tem se materializado, em grande parte, pela utilização de recursos das tecnologias digitais da informação e comunicação (TDIC's), que vêm sendo considerados como recursos didáticos inovadores.

\section{REFLEXões TEÓRICO-CONCEITUAIS}

De início, há que se atentar para o fato de que tratar de inovação educacional, com referência a recursos didáticos inovadores, exige que se expresse o significado e o papel da educação em geral e da educação escolar que estariam sendo assumidos. Isso pelo fato de que não há como se referir a questões educacionais sem que se inclua a sua dimensão teleológica.

Nesse sentido, defende-se que a educação é um trabalho intencional, que tem tido o papel histórico de atualização cultural, pelas novas gerações, num contexto de disputas

\footnotetext{
${ }^{3}$ Nessa quinta versão, o evento foi programado com o envolvimento de outras instituições de educação superior, ou seja, universidades e Institutos Federais de Educação, Ciência e Tecnologia do país.
} 
societárias. A partir disso, defende-se a educação escolar e a escola de qualidade social. Em outras palavras, um espaço histórico cujo objetivo está a serviço da educabilidade dos sujeitos escolares com a assimilação crítica e a reconstrução de conhecimentos científicos, tecnológicos e culturais, acumulados historicamente pela humanidade. Objetivo este que considera as práticas sociais e vivências de diferentes classes, grupos e culturas, com o acolhimento e respeito, portanto, à diversidade econômica, social e cultural. Isso em uma escola que: busca contribuir para a formação de sujeitos autônomos, cidadãos críticos e propositivos, nos âmbitos individual e coletivo; se compromete com a defesa da educação como um direito, a democracia, a ética, a luta contra a dominação e a exploração de qualquer ordem e com o desenvolvimento com sustentabilidade socioeconômica, cultural e ambiental. Obviamente, tudo isso implica um trabalho no contexto das contradições societárias, para, no interior dessas, favorecer o lado relativo a um projeto de sociedade democrática, mais justa e inclusiva.

Nessas condições, os recursos didáticos no trabalho docente que se comprometem com a educação e a escola de qualidade social vão ao encontro de um marco conceitual diferente de outros possíveis, em relação à qualidade da educação. Esse, segundo Candau (2013, p.12), baseia-se na "convicção profunda de que a educação escolar pode colaborar com processos de transformação estrutural da sociedade". Coerentemente com essa posição, ou seja, quando utilizados numa perspectiva dialética, que se caracteriza por movimento, por transformação, os recursos didáticos são considerados de fato inovadores, como se pode constatar a seguir.

Inicialmente, conforme Lopes e Barbosa (2008), muitos estudos sobre inovação a relacionam a questões tecnológicas, macroeconômicas ou organizacionais, respectivamente, nas áreas de engenharia, economia e administração. Assim, pode-se afirmar:

a ideia de inovação como tem sido concebida por muitos se origina no mundo da empresa, da produção, de espaço mercadológico onde inovar tem a ver com sobrevivência, com manter-se em sintonia com o desejo do cliente ou do consumidor. O conceito de inovação já foi pensado por Adam Smith em meados do século XVIII, momento em que o mesmo analisou a relação existente entre a mudança da técnica moderna e o acúmulo de captital, ocasionando a divisão do trabalho e competição." (Nogaro e Battestin, 2016, p.359-360).

No Brasil, pode-se dizer que a ideia de inovação educacional surge com os pioneiros da Escola Nova, tendo sido enfatizada a partir dos anos sessenta, na direção de mudança na educação escolarizada, no seio de uma nova escola numa sociedade moderna. Conforme Messina (2001), a mudança na educação faz parte de um processo de mudança social acelerada, a qual é considerada categoria ou propriedade da sociedade moderna.

Assim, a despeito da questão da diversidade conceitual com a qual o termo inovação é tratado, ele aparece ligado a mudanças intencionais que rompem, em maior ou menor grau, com o equilíbrio existente, em resposta ou não a alguma necessidade na área em que se situa, como a educacional, por exemplo.

Ao tratarem da questão nessa área, vários autores, como Lopes e Barbosa (2008), Teixeira (2010), Borges e Tauchen (2012), Pozzo e Cordeiro (2015) e Battestini e Nogaro (2016) reiteram a polissemia do termo inovação. Essa, no entanto, embora raramente seja mencionado pela literatura na área, relaciona-se a disputas semânticas ligadas a conflitos de interesses de grupos, classes e culturas, porquanto não é abstraída das relações sociais. 
De fato, diferentes sistematizações teóricas em áreas, como a das ciências sociais e da filosofia orientam concepções e tratamentos diferentes para a questão da inovação. $\mathrm{Na}$ filosofia da educação, Dermeval Saviani (1995) problematiza a ideia de inovação educacional, a partir de diferentes concepções filosóficas: humanista - tradicional ou moderna -, analista e dialética.

De acordo com essas concepções, conforme o autor, têm-se níveis de inovação na área educacional, segundo se refiram a graus diferentes de modificações: (a) retoques superficiais ou substanciais, mas apenas nos métodos (versão tradicional e escolanovista); ou (b) utilização de formas "para-institucionais" e/ou "nãoinstitucionalizadas" com o aproveitamento dos avanços tecnológicos; ou, finalmente, (c) alterações nas finalidades da educação, colocada a serviço da transformação social (concepção dialética). Este último nível caracteriza-se por um salto qualitativo que ultrapassaria o significado contido na própria palavra inovação. Nesse nível, pode-se afirmar que a concepção de inovação vai ao encontro do alerta de Garcia (1995) para a sua não neutralidade, que fundamentaria a pergunta: a quem interessa a inovação?

Dessa forma, na área da educação, numa perspectiva dialética, inovar é mais do que introduzir novidades ou mudanças. Implica substituir algo por algo novo, mas tendo em vista finalidades emancipadoras ligadas à transformação social. Daí a afirmação de que, nessa perspectiva, inovar em educação, caracteriza-se, a rigor, como renovar, reinventar, porquanto transformar na direção, portando, de uma educação de qualidade social.

No entanto, parte da literatura na área educacional (p. ex.: Huberman, 1973; Christensen, Horn e Johson, 2012) pode acabar implicando o entendimento da inovação ligado a mudanças apenas no interior do próprio sistema educacional e sem relacioná-lo ao sistema social mais amplo. Isso por não enfatizar a devida atenção para suas finalidades mais amplas, em suas relações com as determinações socioeconômicas, culturais e políticas, em uma dada formação social.

Assim, pode-se acabar reforçando, em oposição até à própria ideia geral com a qual o termo inovação é tratado, a defesa da mera adaptação, supostamente desejada, dos sujeitos escolares às demandas societárias dominantes e predominantes do sistema social mais amplo, em um determinado contexto histórico. Com isso, a defesa, por exemplo, da importância apenas do papel econômico da educação formando sujeitos para um mercado de trabalho, cuja flexibilidade demandaria sujeitos inovadores e empreendedores. Aliás, vale o alerta de Messina (2001) de que, no mundo globalizado, a inovação educacional é um instrumento de regulação e homogeneização social.

No entanto, pelo exposto, os recursos didáticos inovadores, tal como aqui defendidos, devem superar a novidade em si mesma e se relacionarem com rupturas paradigmáticas. E segundo Cunha et al. (2001), "a ruptura necessária propõe a atitude epistemológica que permite reconfigurar conhecimentos para além das regularidades propostas pela modemidade" (p. 37).

Importa registrar ainda o fato de que as denominadas inovações educacionais têm estreita relação com as TDIC's. De fato, conforme Echevarria (2015), acima de tudo, estas reconfiguram "as relações e as ações humanas, tanto individuais quanto coletivas e institucionais" (p. 43).

Por fim, assume-se a posição de que, numa visão dialética, a definição do caráter inovador dos recursos didáticos, no trabalho docente, na educação escolar, demanda a 
sua contextualização na atualidade, ou seja, no âmbito das contradições da contemporaneidade.

A esse propósito, com base em vários autores, como Lima filho (2004), Coutinho, Krawulski e Soares (2007), Hennigen (2007) e Flecha (2011), o termo contemporaneidade, que se utiliza para caracterizar a atualidade, refere-se às transformações sociais, políticas, culturais, científico-tecnológicas e econômicas, no nosso tempo. O seu marco histórico, quando se discute a globalização atual, seria a queda do muro de Berlin, em 1989, e o término da União soviética em 1991 que implicariam o fim de um mundo bipolar. Mas as transformações em questão não representam um todo uniforme e traduzem contradições históricas, em função de projetos diferentes em disputa. Assim, considerações sobre o caráter inovador de recursos didáticos escolares, na contemporaneidade, exige a sua abordagem tendo-se em vista o projeto de educação escolar com o qual se comprometem.

Vale lembrar a ideia de que as consideradas inovações em educação, na atualidade, têm sido marcadas pelas TDIC's. De fato, na caracterização da contemporaneidade, ao lado das categorias da globalização e da pós-modernidade, tem sido considerada a categoria da sociedade da informação. E esta, por sua vez, tem nessas tecnologias uma das suas características principais.

\section{RECURSOS DIDÁTICOS POTENCIALMENTE INOVADORES}

\section{Uma introdução}

Para a identificação de alguns recursos didáticos potencialmente inovadores, há que se retomarem, de forma mais específica, algumas das conclusões do mencionado estudo integrativo exploratório que envolveu, no período de 2010 a 2016: artigos nos periódicos Revista Brasileira de Educação (2011, 2013, 2015), Educação \& Sociedade (2012); trabalhos apresentados nos Grupos de Trabalho (GT) de Didática, Formação de Professores e Currículo, em reuniões anuais da Associação Nacional de Pós-Graduação e Pesquisa em Educação (ANPEd, 2010); e textos nos anais dos Encontros Nacionais de Didática e Prática de Ensino (ENDIPES), neste caso, no período de 2012 e 2014 (XVI ENDIPE, 2012a, 2012b; XVII ENDIPE, 2014a, 2014b, 2014c).

Dos dezenove (19) estudos, cujas palavras-chave incluíam inovação ou inovações, tecnologias educacionais, sociedade do conhecimento, onze (11) abordaram diferentes recursos considerados inovadores. Esses variaram em termos da sua amplitude mais ou menos geral e da sua natureza didático-pedagógica. Assim, foram tratados entre outros, o Programa Institucional de Bolsas de Iniciação à Docência, os ciclos de formação, a interdisciplinaridade, a brinquedoteca, a educação a distância e as tecnologias de comunicação e informação. No entanto, a exceção destes dois últimos casos, que foram abordadas em quatro estudos, os demais recursos o foram em apenas um estudo da amostra indicada.

Quanto às referências bibliográficas dos estudos, foram identificados quase quatrocentos (400) títulos diferentes, correspondentes a quase duzentos e cinquenta (250) autores. Reforçando os sinais da dispersão encontrada, apenas sete textos de sete autores diferentes foram referenciados em mais de um dos estudos. Além disso, cada um dos textos foi indicado por apenas dois estudos. Entre esses textos, destaca- 
se o livro Pedagogia da esperança (Freire, 1996b). Além disso, o autor é mencionado como um dos referenciais teóricos sobre a temática, na amostra pesquisada.

Com base no exposto, foram selecionados para tratamento neste texto, a seguir, dois recursos didáticos no trabalho docente, ou seja, as práticas colaborativas, dialógicas e as TDIC's, tendo-se por pano de fundo serem potencialmente, veja-se bem, potencialmente, inovadores. Quanto a estas últimas, é evidente a ênfase no seu uso, no contexto atual afetado pela pandemia do coronavírus.

Não é demais lembrar que a propriedade de inovação desses recursos, ainda que na direção de apenas possibilidade de travessia para uma escola plena de qualidade social, nem sempre se materializa nos ambientes escolares; a rigor, a sua caracterização como inovadores transcende o discurso teórico, porquanto tem, na prática, o seu critério de verdade.

\section{As práticas colaborativas, dialógicas}

Inicialmente, uma característica da contemporaneidade, na área da educação, pela globalização, refere-se à natureza das políticas públicas e práticas didático-pedagógicas. Essas reforçam um projeto de modernização econômica voltado para o mercado, que se distancia da proposta de escola de qualidade social. No Brasil, e muito contundentemente na América Latina, elas enfatizam um processo global de padronização, que se compromete com a manutenção e expansão do capitalismo contemporâneo, orientado por organismos internacionais.

A rigor, essas políticas e práticas podem ser entendidas pelo que Ball $(2004,2005)$ denomina de "cultura da performatividade", desde que não se desconsidere o alerta de Moreira (2013). Segundo este, não se podem analisar as políticas educacionais, no caso, como absolutamente homogêneas, tendo-se em vista os diferentes lugares e seus respectivos mercados de trabalho diferenciados.

Feita essa ressalva, pela cultura da performatividade, conforme Moreira (2013), ocorre "a ênfase no controle, no desempenho como medida da produtividade, no resultado 'satisfatório' e em uma avaliação que evidencie o alcance de metas previamente definidas. [...] Nesse processo, utilizam-se recompensas e sanções (tanto materiais quanto simbólicas)" (p.70-72). E, para além da dificuldade de entendimento do próprio discurso com o qual são formuladas as políticas curriculares e também de formação de professores, no país, em seu trabalho diário, eles convivem com constrangimentos avaliativos que restringem a sua autonomia e a natureza das práticas didáticopedagógicas que desenvolvem.

A propósito, Moreira (2013) traz à tona o que poderia ser aqui considerado como um recurso de fato inovador, ou seja, o fortalecimento da autonomia docente, fundada no reconhecimento do saber especializado da docência, em oposição àquela cultura da performatividade. Nessa perspectiva, valoriza-se um profissionalismo centrado na colaboração, em que são ouvidas as muitas e variadas vozes, intra e extraescolares, em prol de uma escola democrática em que a prática do diálogo é uma constante.

Aqui, há que se referir aos recursos didáticos nas escolas, em geral, e, particularmente, nas salas de aula que tenham como fundamentos a obra de Paulo Freire, particularmente livros que embasam uma perspectiva de educação dialógica (Freire, 1996a, 1996b, 2003, 2006). 
Coerentemente, na relação entre a universidade e a escola básica, encontram-se as experiências dialógicas em grupos colaborativos, tal como apresentadas por vários estudos, entre os quais o de Couto (2016). A autora discute experiências de formação continuada de professores da rede pública de Minas Gerais pela sua participação em projetos de pesquisa vinculados a um edital da Fundação do Amparo à Pesquisa do Estado de Minas Gerais (FAPEMIG). Pode-se afirmar que as experiências analisadas se enquadram no que se poderia denominar de relação ensino-pesquisa como princípio educativo, na formação continuada de professores. Como um dos resultados dessas experiências, salienta-se o respeito pelos conhecimentos dos professores da escola básica por parte dos professores da universidade e vice-versa. Pode-se considerar que essas experiências exemplificam o reconhecimento do saber especializado do trabalho docente e do não estabelecimento de hierarquias entre saberes e culturas da escola básica e da universidade.

\section{Uso crítico das tecnologias digitais da informação e comunicação}

Entre as características da contemporaneidade, como a sociedade da informação, constata-se um novo estágio de desenvolvimento tecnológico, com as tecnologias digitais da informação e comunicação (TDIC's) que favorecem as interações em tempo real, no espaço das redes. De fato, assiste-se à existência de um novo padrão de sociabilidade, com a comunicação mediada, de forma expressiva, pelos recursos das redes sociais e dos aparelhos celulares.

Contraditoriamente, embora eles facilitem a interação em tempo real e encurtem espaços, comprometem interações presenciais entre pessoas e grupos. Quanto à, pelo menos suposta, democratização da mídia eletrônica e a alfabetização digital por parte dos sujeitos que a utilizam, pode-se afirmar que isso não vem acompanhado da abordagem crítica desses recursos por parte de muitos desses sujeitos.

Nessas condições, recursos didáticos inovadores, no sentido de se se ter a presença das TDIC's no trabalho docente, comprometido com uma educação de qualidade social, envolvem as práticas escolares a respeito, consoantes com a proposta de uma Pedagogia Social da Tecnologia. Essa, tal como sugerida por Tavares e Gomes (2014), congrega discussões e sugestões de propostas sobre a matéria.

Coerente com a Pedagogia Social da Tecnologia, o uso das tecnologias em pauta, nas práticas escolares inovadoras, naquela perspectiva dialética, deve implicar, de início, o reconhecimento de que: (a) questões educacionais não podem ser equacionadas nos limites da modernização econômica e dos interesses tecnológicos; (b) embora essas tecnologias tenham entrada franca na secretaria da escola, nos grupos de estudo ou nos núcleos de educação a distância, isso não veio ocorrendo, na mesma proporção, quando se trata da educação nas salas de aula, sobretudo com o reconhecimento do seu caráter ou não de inovações ${ }^{4}$.

Acrescentando, o uso das TDIC's: (a) não é fator absoluto de equalização social nem condição suficiente ou mesmo necessária para o trabalho docente e a formação de professores com criticidade e criatividade; (b) imprime características da lógica própria dessas tecnologias aos conteúdos de ensino tratados por elas; (c) não raro inclui o

\footnotetext{
4 Com ressalva para o momento atual da pandemia pelo coronavírus, no qual as TDIC's têm estado plenamente presentes nas atividades escolares.
} 
equívoco de se afirmar que esse uso, na formação de novos trabalhadores, estaria sendo absolutamente requerido por um processo didático-pedagógico que se considerasse não atrasado, em função do atual estágio de desenvolvimento tecnológico; (d) tem potencial formativo na direção aqui defendida, desde que inclua o entendimento sócio-histórico e a leitura crítica do novo modo de desenvolvimento, constituído por um novo paradigma tecnológico, tal como discutido por Castells (1999).

Finalmente, há que se referir às lições da utilização das TDIC's na educação escolar, tal como vem sendo condicionada pela pandemia pelo coronavírus.

\section{AS TECNOLOGIAS DIGITAIS DA INFORMAÇÃO E COMUNICAÇÃO NA ESCOLA, NO CONTEXTO DA PANDEMIA ATUAL}

\section{Primeira aproximação}

A crise mundial afetada pelo coronavírus cuja pandemia tem demandado 0 distanciamento social entre as pessoas envolve uma série de cuidados os quais têm requerido mudanças em todos os setores da vida, incluído o da educação escolar.

Com isso, os sujeitos escolares têm se visto às voltas com o denominado ensino remoto, com interações síncronas entre estudantes, professores, gestores e funcionários administrativos nas escolas. Essas interações têm sido mediadas por tecnologias da informação e comunicação, sobretudo as digitais (TDIC's). E nessas condições, a presença marcante dessas tecnologias no trabalho docente e na educação escolar, em geral, tem se destacado como alternativa metodológica considerada inovadora na área educacional. Além disso, com elas, tem-se procurado garantir a continuidade, pelo menos mínima, dos processos de ensino e aprendizagem na educação escolar.

Sinaliza-se, então, algo importante, ou seja, a necessidade de se discutirem os limites da positividade dessas mudanças, tendo-se em vista o seu caráter mais ou menos inovador na direção daquela educação escolar de qualidade social.

A esse propósito, cabe situar o conteúdo do número 1, deste ano de 2020, da revista online c da Associação Nacional de Política e Administração da Educação (ANPAE) que envolve um conjunto expressivo de vídeos, áudios e texto com depoimentos por parte de estudantes, seus pais ou responsáveis, professores, gestores e pesquisadores de diferentes regiões do país, sobre a educação em tempos de pandemia.

No conteúdo da revista, no tratamento crítico das mudanças atuais, os sujeitos escolares chamam a atenção para várias questões e limites relativos a elas, sugerindo desafios cuja superação depende, por certo, de luta, esforço e trabalho coletivos na área. Evidenciam que as mudanças afetam a qualidade da educação, a identidade e o trabalho docentes com suas restrições objetivas e subjetivas. Assim, o conjunto constituído pelos vídeos, áudios e textos da Revista e pauta possibilitam uma reflexão ampla e profunda sobre a condição do denominado ensino remoto nas escolas do país, no momento atual.

Inicialmente, pelo estudo do conteúdo da revista, o qual vai ao encontro das práticas que estão sendo vivenciadas não apenas na educação básica, mas também na superior, nas escolas do país, evidenciam-se vários aspectos contraditórios sobre ao uso das mencionadas tecnologias na educação escolar, abordados de forma sintética a seguir.

Em primeiro lugar, as mudanças em curso desvelam, o que parece muito positivo, o compromisso da escola com o ensino e a aprendizagem do corpo discente. Os sujeitos 
escolares têm buscado aprender com as condições atuais e não têm medido esforços para atenderem às novas demandas postas à educação escolar. Por outro lado, à luz da defesa da educação de qualidade social, ocorre o vivivel aumento da precarização do trabalho docente e da ansiedade e do medo, expressos pelos sujeitos escolares, pelo possível fracasso no ensino e na aprendizagem das suas alunas e dos seus alunos.

Em segundo lugar, as mudanças que ocorrem evidenciam de forma contundente, o que também é positivo, as desigualdades sociais que impõem limites ao acesso à educação escolar e à continuidade dos estudos, por parte de grande contingente do corpo discente. Fica também claro que as mudanças propostas não têm sido capazes de atenuar, mas acabam acentuando as desigualdades na educação, que, obviamente, reproduzem as desigualdades sociais. Mais uma vez estas ficam agudizadas, acentuadas, pelos limites objetivos e subjetivos de existência de uma grande porcentagem de estudantes brasileiros e, também, do corpo docente, ao lado das, não raro, parcas condições gerais de trabalho nas escolas. Assim, apesar do trabalho amplo e criativo que vem sendo desenvolvido nas escolas, o abandono dos estudos por parte expressiva do corpo discente tem se mostrado evidente no momento atual; e parece provável a continuidade desse abandono, mesmo depois da volta às aulas presenciais.

Acrescenta-se que as circunstâncias atuais têm evidenciado a ampliação do domínio e a apropriação de TDIC's, por parte da escola e dos seus sujeitos. Positivamente, dada a natureza dos espaços, tempos e sujeitos escolares, essa apropriação, ainda que de forma relativamente tímida, dadas aquelas desigualdades referidas, não se tem feito de forma acrítica; o que se pode estender para uma compreensão educativa do estágio atual de desenvolvimento tecnológico, em outros setores societários.

Por outro lado, paralelamente, descortina-se um amplo mercado de mídias e usuários na educação escolar. Em detrimento de uma educação de qualidade social, essa situação pode significar, entre outros aspectos: a ênfase na educação como um mero espaço de mercado corporativo emergente; a concepção de educação como um bem de consumo e não um direito social inegociável; o reforço ao domínio de informações não processadas como conhecimentos, dadas limitações próprias da veiculação de conteúdos curriculares pelas mídias em pauta; a contração da função socializadora da escola e das relações intersubjetivas no trabalho escolar, em geral, e no trabalho docente em particular; o descaso pelo trabalho coletivo e solidário, em prol de um individualismo perverso em termos morais e éticos. Esses aspectos precisam ser considerados na defesa por uma educação de qualidade social.

Quanto a elementos mais específicos relativos aos processos de ensino e aprendizagem, tem-se ainda um conjunto de mudanças que não deixam de ser expressivas. Elas incluem questões de linguagem, técnicas, procedimento, recursos didáticos de natureza físico-material propriamente dita, relação professora/professoraluna/aluno, planos e programação de conteúdos.

\section{Uma nova linguagem e outros aspectos de natureza didático- curricular}

De início, há que se considerar o fato de a utilização das tecnologias mencionadas na educação escolar, no contexto da pandemia pelo coronavírus, incluir toda uma linguagem e vocabulário novos, ampliando as expressões já muito conhecidas, entre as quais: educação a distância, vídeos educativos, tele aulas. 
Correndo o risco de errar, poder-se-ia dizer que, à exceção do já histórico Sistema de Educação a Distância, existente mesmo antes dessa pandemia, as expressões mencionadas não contemplavam um amplo conjunto de recursos variados de ensino e aprendizagem muito articulados entre si. Eles também não competiam em igualdade de condição com a educação presencial, ou até mesmo, semipresencial, e nem pretendiam essa igualdade. Eram considerados recursos emergenciais, com objetivos diferentes daqueles na condição de ensino e aprendizagem regulares.

$\mathrm{Na}$ situação atual, que impõe a necessidade do distanciamento social, de forma meio abrupta nas práticas escolares, os sujeitos da educação vêm sendo bombardeados com uma nova linguagem e um novo vocabulário referidos a um conjunto de recursos midiáticos, virtuais, disponibilizados pela web. Esses passam a dominar os processos educativos escolares e a subsumirem aqueles com os quais se estava familiarizado. Também, não raro, são apresentados como substitutos valiosos e até mesmo desejados em relação à educação presencial. Essa nova linguagem e esse novo vocabulário juntamente com os novos recursos constituem um conjunto organicamente articulado e inserido, fundamentalmente, na ampla área tecnológica.

Com aquelas expressões já histórias, são consagradas novas expressões, tais como: ensino remoto; aulas remotas; ensino virtual ou on-line. Elas expressam um conjunto de recursos tornados didáticos que se expandem e que se lhes correspondem, tais como: web conferência, web aula, aulas virtuais, aulas on-line, A esses ainda se une um conjunto de recursos acessados por ferramentas como computadores e celulares os quais já contemplavam um novo modo de sociabilidade na contemporaneidade. Entre eles, têm-se: e-mail, chat, facebook, blog, instagram e os mais variados tipos de aplicativos. Além disso, os ambientes físicos das salas de aula e das reuniões pedagógicas são substituídos pelos home offíces, a expressão interação professora/professor-aluna/aluno pela expressão aprendizagem conectada, ou conectividade didático-pedagógica em plataformas virtuais e as técnicas e os procedimentos didáticos por protocolos de ensino.

Nesse cenário, salienta-se, de forma contundente, a necessidade e a realização da formação continuada dos sujeitos escolares, considerada, inclusive a velocidade com a qual o desenvolvimento tecnológico nos impõe novas aprendizagens. Isso vem sendo seguido, positivamente, de uma mobilização expressiva na formação docente, como evidenciam os sites das mais diversas instituições de ensino do país, seja da educação básica, seja da superior.

No entanto, o ritmo e a natureza das mudanças que estão ocorrendo podem reduzir a visão da professora e do professor como consumidores, youtubers e blogueiros e de estudantes como usuários. Além disso, essas mudanças influenciam, cada vez mais, a já mencionada precarização do trabalho docente pelo qual cada professora, cada professor passa a ser chamada ou chamado a realizar um sobretrabalho na construção de videoaulas e aulas on-line para um grande contingente de alunas e alunos. Novamente, esses aspectos colocam em risco a qualidade social da educação.

De forma mais específica constatam-se, ainda:

- a posição da professora e do professor, como principais mediadores de alunas e alunos, em relação aos conteúdos curriculares, sendo relegada a segundo plano, pelo papel que as TDIC's passam a desempenhar. Isso reforça, equivocamente, um reducionismo em termos das funções sociais da escola e a ideia da possível dispensa da professora, do professor. Por outro lado, o uso dessas tecnologias da 
forma intensiva com a qual tem ocorrido na educação escolar, tal como evidencia conteúdo da mencionada revista, vem sinalizando o reconhecimento da importância e a valorização do trabalho docente, sobretudo por parte dos pais e responsáveis de alunas e alunos;

- a ocorrência do distanciamento intersubjetivo entre os sujeitos escolares ao lado da possibilidade de contato entre eles, em tempo real, independentemente dos espaços geográficos em que estejam;

- o abandono da escola por parte das famílias das alunas e dos alunos, ao lado da ampliação do conhecimento das famílias e das comunidades por parte da escola;

- as limitações objetivas e subjetivas das escolas para a construção de aulas em novas formas didáticas, condicionando a divulgação de aulas padronizadas. No entanto, o reconhecimento dessa situação incentivando o esforço dos sujeitos escolares na construção e busca de legitimação de currículos (conteúdos e métodos) cuja flexibilidade, em atendimento às diferenças culturais e regionais, seja facilitada e não constrangida pelos recursos tecnológicos.

\section{À GUISA DE CONCLUSÃo}

No presente texto, discute-se que as inovações educacionais não são neutras porquanto não são abstraídas do contexto social mais amplo. De fato, as mudanças na educação escolar não são destituídas do aspecto teleológico e são orgânicas às contradições societárias no sistema social mais amplo. Elas podem evidenciar adaptações ou transformações, consoantes com aquelas contradições. Numa visão dialética, os recursos didáticos no trabalho docente têm o caráter de inovadores na dependência das suas finalidades que reforçam ou não transformações na direção da qualidade social da educação escolar. As práticas colaborativas, dialógicas, e as TDIC's, nos limites evidenciados neste texto, contam com potencial na direção daquela qualidade.

No caso das TDIC's, a sua utilização bastante intensiva nas escolas do país, nas circunstâncias da pandemia pelo coronavírus, vem desvelando, de forma muito contundente, positividades e negatividades naquela direção. Mas fica desvelado que a sua positividade depende em muito da inclusão digital para além da mera alfabetização tecnológica, por parte dos sujeitos escolares. Por aquela, os sujeitos escolares aprendem a utilizar e se relacionar de forma crítica com as TDIC's, na educação escolar. Aliás, tal como vem sendo discutida na literatura, particularmente na área tecnológica, a inclusão digital não se restringe apenas ao acesso a equipamentos e ao domínio técnico das tecnologias. Conforme Lemos (2016, p 42), "Incluir não deve ser apenas uma simples ação de formação técnica dos aplicativos, [...] mas um trabalho de desenvolvimento das habilidades cognitivas, transformando informação em conhecimento, transformando utilização em apropriação".

Importa lembrar também o fato de que a inclusão digital como um direito fundamental e em suas relações estreitas com a cidadania e a democracia vem sendo discutido há muito, na área do direito, tal como em Serau Júnior e Gonçalves (2003), Pereira e Nascimento (2017), Nonato (2020). Mas, para tal, há que se enfrentarem alguns desafios na educação escolar: propiciar a disponibilização efetiva e crítica das TDIC's para o corpo discente e docente no ambiente escolar; fortalecer a pesquisa para a construção de recursos digitais abertos, ou seja, de domínio público ou com licença aberta; construir espaços públicos que disponibilizem o acesso e a apropriação crítica de recursos 
tecnológicos, nos âmbitos individual e coletivo, sobretudo por parte dos sujeitos escolares que não contam com eles no seu ambiente mais privado. Obviamente, isso depende de políticas públicas, conquistadas não sem intensa e extensa luta coletiva na área da educação.

\section{REFERÊNCIAS}

ABMES. III Fórum Mundial de Educação Profissional e Tecnológica. Disponível em: https://tinyurl.com/ABMES-III-FORUM. Acesso em: 15 set. 2020.

ANPED. Educação no Brasil - O balanço de uma década: 17 a 20 de outubro de 2010. Disponível em: http://33reuniao.anped.org.br/internas/ver/trabalhos-gt04. Acesso em: jul. 2016.

BALL, S. J. Performatividade, privatização e o pós-Estado do bem-estar. Educação \& Sociedade, Campinas, v. 25, n. 89, p. 1105-1126, set./dez. 2004. Disponível em: https://tinyurl.com/BALL-2004. Acesso em: set. 2020.

BALL, S. J. Profissionalismo, gerencialismo e performatividade. Cadernos de Pesquisa, São Paulo, v. 35, n. 126, p. 539-564, set./dez. 2005. Disponível em: https:/www.scielo.br/pdf/cp//35n126/a02n126.pdf. Acesso em:15 set. 2020.

BORGES, D.S.; TAUCHEN, G. Inovação no ensino universitário: propostas e cenários. In: XVI ENDIPE. Livro 1. Araraquara: Junqueira \& Marin Editores, 2012.

BVS - BIBLIOTECA VIRTUAL EM SAÚDE. XVIII ENDIPE-Endipe 2016-Encontro Nacional de Didática e Práticas de Ensino. Disponível em:

http:/www.bvseps.icict.fiocruz.br/direve/resource/18294\#.X2eFMriOlzc. Acesso em: 15 set. 2020.

CANDAU, V. M. Currículo, didática e formação de professores: uma teia de ideias-força e perspectivas de futuro. In: OLIVEIRA, M. R. N. S.; PACHECO, J. A. (Orgs.). Currículo, didática e formação de professores. Campinas: Papirus, 2013. p.7-19.

CASTELLS, M. A era da informação: economia, sociedade e cultura. São Paulo: Paz e Terra, 1999. (3 v.).

CIM. V Congresso de Inovação e Metodologias no Ensino Superior e Tecnológico. Disponível em: https://www.ufmg.br/giz/congresso-de-inovacao-em-metodologias. Acesso em: 15 set. 2020.

COUTO, H.R.P. Desenvolvimento profissional de professores da educação básica inseridos em projetos de pesquisa. 2016. 106p. Dissertação (Mestrado em Educação Tecnológica). Centro Federal de Educação Tecnológica de Minas Gerais, Belo Horizonte, 2016.

CHRISTENSEN, C; HORN, M.B., JOHNSON, C.W. Disrupting class: how disruptive innovation will change the way world learns. 4. ed. Ney York: McGraw Hill, 2012.

COUTINHO, M.C.; KRAWULSKI. E.; SOARES, H.P. Identidade e trabalho na contemporaneidade: repensando articulações possíveis. Psicologia \& Sociedade, Recife, v.19, p.29-37. 2007 (Edição Especial 1). Disponível em: https://www.scielo.br/pdf/psoc/v19nspe/v19nspea06. Acesso em: set. 2020.

CUNHA, M.I. et al. Inovações pedagógicas na formação inicial de professores. In: FERNANTES, C.M.B. (Org.). Educação superior: travessias e atravessamentos. Canoas: Ed ULBRA, 2001. p. 33-90.

ECHEVARRÍA, J. A escola contínua e o trabalho no espaço-tempo eletrônico. In. INBERNÓN, F. e JARANTA, B. Pensando no futuro da educação: uma nova escola para o século XXII. Porto Alegre: Penso, 2015.

EDUCAÇÃO BÁSICA EM FOCO (on-line). Associação Nacional de Política e Administração da Educação, 2020. Disponível em: https://educacaobasicaemfoco.net.br. Acesso em: 31 jul. 2020.

EDUCAÇÃO \& SOCIEDADE, Campinas: CEDES, v. 33, n.121, out./dez. 2012. Disponível em: https:/www.scielo.br/scielo.php?script=sci_issues\&pid=0101-7330\&lng=en\&nrm=iso. Acesso em: 10 jul. 2016

XVI ENDIPE. Livro 1. Araraquara: Junqueira \& Marin Editores, 2012a.

XVI ENDIPE. Livro 3. Araraquara: Junqueira \& Marin Editores, 2012b. 
XVII ENDIPE. Didática e Prática de Ensino: diálogos sobre a escola, a formação de professores e a sociedade. Fortaleza: EdUECE, 2014a. (Livro 4).

XVII ENDIPE. Didática e Prática de Ensino na relação com a escola. Fortaleza: EdUECE, 2014b. (Livro 1).

XVII ENDIPE. Didática e Prática de Ensino na relação com a formação de professores. Fortaleza: EdUECE, 2014c. (Livro 2).

XVII ENDIPE. A didática e a prática de ensino nas relações entre escola, formação de professores e sociedade: caderno de programação. Fortaleza: CE/UECE, 2014d.

FERNANDES, F.C.M. Gestão dos Institutos Federais: o desafio do centenário da Rede Federal de Educação Profissional e Tecnológica. Holos, Natal, ano 25, v.2, p.3-9, nov. 2009. Disponível em: www2.ifrn.edu.br/ojs/index.php/HOLOS/article/viewFile/267/187. Acesso em: 15 set. 2020.

FLECHA, R.D. Modernidade, contemporaneidade e subjetividade. Sapere Aude, Belo Horizonte, v.2, n.3, p-28-43. 2011. 1ํ sem. 2011. Disponível em: http://periodicos.pucminas.br/index.php/SapereAude/article/view/2264. Acesso em: 15 set. 2020.

FREIRE, P. Educação como prática da liberdade. 29. ed. Rio de Janeiro: Paz e Terra, 2006.

FREIRE, P. Pedagogia da autonomia: saberes necessários à prática educativa. Rio de Janeiro: Paz e Terra, 1996a.

FREIRE, P. Pedagogia da esperança: um encontro com a pedagogia do oprimido. Rio de Janeiro: Paz e Terra, $1996 \mathrm{~b}$.

FREIRE, P. Pedagogia do oprimido. 35. ed. Rio de Janeiro: Paz e Terra, 2003.

GARCIA, W.E. (Org.). 3. ed. Inovação educacional no Brasil: problemas e perspectivas. São Paulo: Cortez, 1995.

HENNIGEN, I. A contemporaneidade e as novas perspectivas para a produção de conhecimentos. Cadernos de Educação, v.29. p. 192-208. Jul./dez. 2007. Disponível em: http:/fae.ufpel.edu.br/caduc/downloads/n29/11.pdf. Acesso em: 15 set. 2020.

HUBERMAN, A.M. Como se realizam das mudanças em educação: subsídios para o estudo da inovação. São Paulo: Cultrix, 1973.

LIMA FILHO, D. L. Dimensões e limites da globalização. Petrópolis: Vozes, 2004.

LOPES, D.P.T.; BARBOSA, A.C.Q. Inovação: conceitos, metodologias e aplicabilidade. Articulando um construto à formulação de políticas públicas - uma reflexão sobre a Lei de Inovação de Minas Gerais. In: SEMINÁRIO SOBRE A ECONOMIA MINEIRA, 13, 2008, Belo Horizonte. Anais. Belo Horizonte: Cedeplar/UFMG, 2008.

MESSINA, G. Mudança e inovação educacional: notas para reflexão. Cadernos de Pesquisa, São Paulo, n.114, p.221-233, nov. 2001. Disponível em: https://www.scielo.br/pdt/cp/n114/a10n114.pdf. Acesso em: 15 set. 2020.

MOREIRA, A.F.B. Em busca da autonomia docente nas práticas curriculares no Brasil. In: OLIVEIRA, M.R.N.S.; PACHECO, J.A. (Orgs.). Currículo, didática e formação de professores. Campinas: Papirus, 2013. p. 69-96.

NONATO, A. A. O acesso à internet é um direito fundamental? Disponível em: https://tinyurl.com/y5wtpsls. Acesso em: 15 set. 2020.

BATTESTIN, C.; NOGARO, A. Sentidos e contornos da inovação na educação. Holos, Natal, ano 32, v. 2, p.357-372. 2016. Disponível em: https://tinyurl.com/y3du4n7o. Acesso em: 15 set. 2020.

PEREIRA, M. N.; NASCIMENTO, V.R. O direito à inclusão digital: o papel da cidadania online em matéria ambiental para a construção de uma democracia direta. Revista de Direito Público, UEL, Londrina, v.12, n. 2, p, 130-154, ago. 2017. Disponível em: http://www.uel.br/revistas/uel/index.php/direitopub/issue/view/1333. Acesso em: 15 set.2020.

POZZO D.N.; CORDEIRO, M.M. O processo de inovação na educação: um estudo em uma organização educacional. Revista do CEPE, Santa Cruz do Sul, n.42, p.132-150. jul./dez. 2015. Disponível em: https://online.unisc.br/seer/index.php/cepe/article/download/5567. Acesso em: 15 set. 2020. 
RBE - REVISTA BRASILEIRA DE EDUCAÇÃO. Rio de Janeiro, ANPEd, v.16, n.48, set./dez. 2011. Disponível em: https://tinyurl.com/RBE-V16-N48. Acesso em: jul. 2016.

RBE - REVISTA BRASILEIRA DE EDUCAÇÃO. Rio de Janeiro, ANPEd, v.18, n.52, jan./mar. 2013. Disponível em: https://tinyurl.com/RBE-V18-N52. Acesso em: jul. 2016.

RBE - REVISTA BRASILEIRA DE EDUCAÇÃO. Rio de Janeiro, ANPEd, v.20, n.62, jul./set. 2015. Disponível em: https://tinyurl.com/RBE-V20-N62. Acesso em: jul. 2016.

SAVIANI, D. A filosofia da educação e o problema da inovação em educação. In: GARCIA, W.E. (Org.). 3. ed. Inovação educacional no Brasil: problemas e perspectivas. São Paulo: Cortez, 1995.

SARAU JUNIOR, M. A.; GONÇALVES, V. H.P. A "inclusão digital" e os direitos sociais perante. Revista Brasileira de Direito Constitucional, Escola Superior de Direito Constitucional, São Paulo, n. 2, p. 244-252. jul./dez. 2003. (Monografias). Disponível em: https://tinyurl.com/SARAU-GONCALVES-2013. Acesso em: 15 set. 2020.

TAVARES, R.H e GOMES, S. Sociedade, educação e redes: desafios à formação crítica. Araraquara: Junqueira \& Marin Editores, 2014.

TEIXEIRA, C. M. F. Inovar é preciso: concepções de inovação em educação dos programas Proinfo, Enlaces e Educar. 2010. 90 p. Dissertação. (Mestrado em Educação). Universidade do Estado de Santa Catarina, Florianópolis, 2010.

Data da submissão: 04/10/2020.

Data da aprovação: 15/03/2021. 